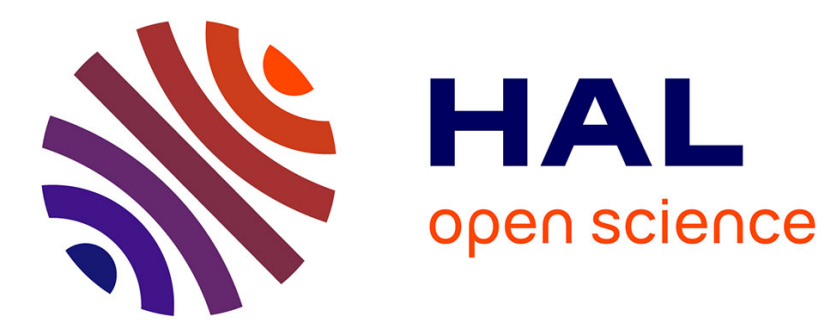

\title{
An experimental study on the effects of two-dimensional positive surface defects on the laminar-turbulent transition of a sucked boundary layer
}

Jeanne Methel, Maxime Forte, Olivier Vermeersch, Grégoire Casalis

\section{- To cite this version:}

Jeanne Methel, Maxime Forte, Olivier Vermeersch, Grégoire Casalis. An experimental study on the effects of two-dimensional positive surface defects on the laminar-turbulent transition of a sucked boundary layer. Experiments in Fluids, 2019, 60 (94), pp.1-18. 10.1007/s00348-019-2741-2 . hal02299012

\section{HAL Id: hal-02299012 \\ https://hal.science/hal-02299012}

Submitted on 27 Sep 2019

HAL is a multi-disciplinary open access archive for the deposit and dissemination of scientific research documents, whether they are published or not. The documents may come from teaching and research institutions in France or abroad, or from public or private research centers.
L'archive ouverte pluridisciplinaire HAL, est destinée au dépôt et à la diffusion de documents scientifiques de niveau recherche, publiés ou non, émanant des établissements d'enseignement et de recherche français ou étrangers, des laboratoires publics ou privés. 


\title{
An experimental study on the effects of two-dimensional positive surface defects on the laminar-turbulent transition of a sucked boundary layer
}

\author{
Jeanne Methel · Maxime Forte · Olivier Vermeersch • Gregoire Casalis \\ Received: date / Accepted: date
}

Abstract Laminar-turbulent transition can be effectively delayed using Laminar Flow Control (LFC) by boundary layer suction. However, major obstacles to the industrial implementation of this technique are related to practical limitations such as proper integration of the suction system or unreliability of current design tools. The influence of surface discontinuities that can arise from installing an LFC system (and that can potentially cancel or deteriorate its stabilizing effect on the boundary layer) is scarcely documented in the open literature, adding to the complexity of improving numerical models. The present investigation therefore focuses on experimentally characterizing the effects of surface defects on the laminar-turbulent tran-

J. Methel

E-mail: Jeanne.Methel@onera.fr

M. Forte

E-mail: Maxime.Forte@onera.fr sition of a sucked boundary layer in a two-dimensional flow in an effort to address some of the issues mentioned above. The experimental facility and protocol for conducting this transition study are first presented, followed by a baseline characterization of the effects of wall suction only on transition. Surface defects, in the form of cylindrical roughness elements (wires) for this preliminary study, are then introduced on the flat plate and their effects, coupled to those of wall suction, on boundary layer stability are discussed. Based on this study's test cases, results show that, in the presence of the wires, suction is only effective up to similar critical relative heights as in the cases without suction. In the case where the onset of transition coincides with the position of the surface defect, spectral analysis of the flow immediately downstream of the defect for all suction configurations reveals a range of amplified high frequencies in addition to or in place of the nat- 


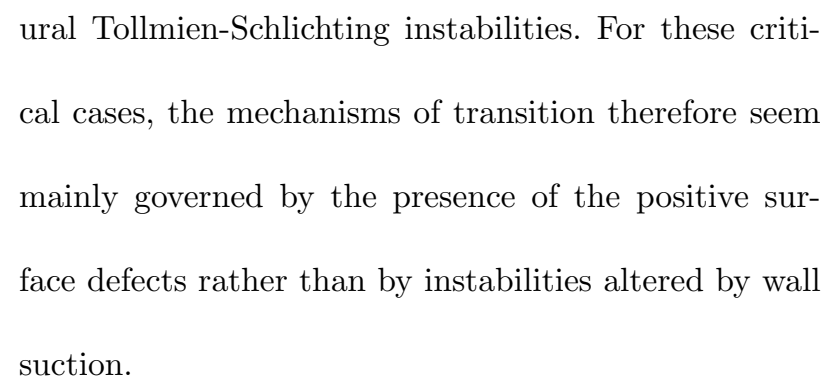

Keywords laminar-turbulent transition · boundary layer suction · Laminar Flow Control · surface defects

$\alpha \quad$ Wave number (complex variable)

$\delta_{1} \quad$ Displacement thickness

$\delta_{99}$ Boundary layer thickness at $0.99 U_{e}$

$\omega \quad$ Frequency

$\theta \quad$ Momentum thickness

Roman Symbols

\section{$C p \quad$ Pressure coefficient}

d Suction hole diameter

$H \quad$ Shape factor

$h \quad$ Wire diameter

LST Linear Stability Theory

PSDPower Spectral Density

\section{$p \quad$ Porosity}

Re Reynolds number

$U \quad$ Streamwise $(x)$ component of velocity

$u^{\prime} \quad$ Streamwise $(x)$ component of velocity fluctuation

$x \quad$ Streamwise coordinate

y Normal coordinate to the flate plate wall

z Spanwise coordinate

Subscripts and Superscripts

\author{
$\infty \quad$ Freestream \\ e Boundary layer edge \\ $S D$ Surface defect \\ $x T$ Transition location
}

\section{Introduction}

The projected increase in air traffic volume coupled with the need to reduce aviation's fuel consumption for environmental sustainability has led to a renewed interest in laminar flow research. Different approaches can be used to maximize the extent of laminar flow regions and delay laminar-turbulent transition: Natural Laminar Flow (NLF), where airfoil profile geometry is optimized to generate a favorable pressure gradient; Laminar Flow Control (LFC) where an active form of control is used to maintain a laminar boundary layer over the 
entire profile; and Hybrid Laminar Flow (HLFC) which consists in a combination of LFC in the fore section of the profile followed by an NLF geometry. In particular, the basic objective of these flow control techniques is to reduce skin friction drag, which can represent approximately $50 \%$ of the total drag of a typical civil transport aircraft [Mar01], by delaying the laminar-turbulent transition of the boundary layer. One LFC method is to stabilize the boundary layer using wall suction by making the mean streamwise velocity profile fuller.

Test flights reported by Head [Hea55] performed as early as in the 1950s demonstrated the effectiveness of boundary layer suction through a sheet of porous nylon material attached over the suction box in the wing. Regions of the wing that were normally turbulent without any active flow control were found to be laminar when suction was applied. In addition to LFC configurations using porous sheets, in-flight investigations were also done on the effectiveness of suction through slots, such as on the X-21A or X-21B. Laminar flow over more than $50 \%$ chord was successfully achieved across Reynolds numbers ranging from $20 \cdot 10^{6}$ to $40 \cdot 10^{6}$ according to Joslin [Jos98]. However, premature transition was often triggered [Bra99] despite the care taken to ensure surface smoothness during both manufacturing and operation. In response to this issue, conservative surface tolerances were defined but did not account for local flow conditions [NG66]. Eventually, despite the program's success in proving slot-suction effectiveness, the uncertainties related to in-service operation and sensitivity to surface defects halted the commercial application of this technology.

As manufacturing capabilities improved, porous materials such as nylon were replaced by perforated metallic sheets (typically stainless steel or titanium). Flight tests were subsequently conducted on a Dassault Falcon 50 as described by Bulgubure and Arnal [BA92] in the late 1980s in France and on a B757 in the early 1990s in the United States [Mad91]. In both cases, laminarturbulent transition was effectively delayed, thus demonstrating the feasibility of using wall suction on a commercial aircraft's wing using modern manufacturing techniques. In particular, Maddalon reports that laminar flow was maintained for up to $65 \%$ of the B757 wing chord, corresponding to a projected $6 \%$ drag reduction at the scale of the aircraft. Unfortunately, discrepancies between predicted results and experimental data highlighted limitations in the available design tools, leading to further test campaigns but commercial implementation.

In between the two periods of flight testing campaigns mentioned above, wind tunnel investigations were also conducted on the different parameters that could affect suction performance. Critical suction (sometimes re- 
ferred to as oversuction), defined as the rate of suction above which suction loses effectiveness and starts to destabilize the boundary layer, can mainly be affected by five parameters: suction flow rate as well as hole size, spacing, geometry and wall-normal inclination [Jos98].

In an experimental investigation illustrating oversuction, Gregory [Gre62] found that depending on the suction flow rate, the interactions between the horseshoe vortices forming around the perforations could either destabilize or stabilize the boundary layer. On the other hand, another study by MacManus [ME96] that investigated the effects of variability in hole cross-sectional shape (due to manufacturing for example) showed that transition was not significantly affected by this parameter.

Closely related to hole geometry, pressure drop can be optimized to reduce the performance requirements on the suction pump and also minimize the possibility of outflow from the suction chambers that could re-enter the boundary layer. A study on the design of a perforated sheet for LFC applications by Reneaux and Blanchard [RB92] concluded that the hole diameter with respect to boundary layer thickness was an important parameter to optimize. If hole sizes were too small, the sucked flow could be overaccelerated and transition triggered prematurely. On the other hand, a large hole size could result in too low of a pressure drop, af- fecting pumping requirements and the risks of outflow mentioned above.

Practical LFC applications through suction panels require dividing the suction area into smaller subregions to maintain the wing box's structural integrity and enable adjustment of local suction parameters in the case of a changing external pressure distribution. Juillen et al. [JCA95] set up an experiment (in the same subsonic wind tunnel facility and with the same flat plate used in the present paper) to study the effects of discontinuous suction on transition. Further details about both the facility and flat plate will be given in the following section. Even with a total suction mass flow rate held constant at the low value of $0.4 \mathrm{~g} . \mathrm{s}^{-1}$, the authors found that the suction distribution over the nine different chambers had a strong influence on transition location. In particular, if suction were applied upstream of the amplification of secondary instabilities, transition could be significantly delayed. For example, one configuration with suction applied over only two chambers moved the transition location $35 \%$ further downstream from the original transition location without suction with respect to the leading edge.

A follow-up study on the influence of the perforated sheet's porosity on transition concluded that this parameter had less of an effect than suction distribution.

However, other studies, by Heinrich et al. [HCK88] or 
Choudhari [Cho94] for example, have found that a porous wall without any suction, which can also be referred to as wall-admittance or a passive porous wall, could affect boundary layer stability. Research into how this phenomenon could be used as a flow control technique itself has led to numerical studies, such as those by Carpenter [CP01] and Tilton et al. [TC15], where a passive porous wall was found to generally destabilize the boundary layer. In the present study, the effect of porosity without suction was observed and will briefly be mentioned; however, this issue will be addressed in more details in a future paper focused primarily on this topic.

Implementing LFC is a proven and effective method to delay laminar-turbulent transition. However, commercial use of this technology is still hindered by practical limitations such as integration of the suction system in the aircraft or unreliability of the design tools due to incomplete understanding of the physics involved. The influence of surface defects (due to manufacturing or in-service operation, for example) on the effectiveness of an LFC system is related to both issues mentioned above. Furthermore, no experimental data reporting the effects of surface imperfections on a sucked boundary layer are currently available in the open literature.

In general, surface defects are known to destabilize a "natural" boundary layer (i.e., without suction and without surface defects) and trigger premature transition.

During test flights on the X-21 in the 1960s, Nenni and Gluyas [NG66] established transition criteria in terms of Reynolds numbers based on the height of backwardand forward-facing steps or streamwise length of gaps, and the freestream velocity and kinematic viscosity. In this case, the critical Reynolds number for a backwardfacing step, a forward-facing step and a rectangular gap is equal to 900,1800 and 15,000 respectively. Although these criteria are still used today, later experimental and numerical studies revealed more appropriate parameters to define transition criteria such as the two-dimensional surface defect's height- or depth-towidth ratio and local, instead of freestream, flow velocity ([BPFB16] and [CRK15]).

As shown by the criteria above from Nenni and Gluyas, experiments, by Wang and Gaster [WG05] for example, or numerical studies by Perraud $\left[\mathrm{PSR}^{+} 05\right]$ show that backward-facing steps, in general, tend to destabilize the boundary layer more significantly than forwardfacing steps. A receptivity study performed by Dovgal et al. [DKM94] also confirmed this trend as authors measured levels of perturbations induced by backwardfacing steps approximately twice as large as those found for forward-facing steps. In a set of numerical simulations by Rizzetta and Visbal [RV14], where the dif- 
ference between the effects of the two types of steps was not as distinguishable as in the previous studies mentioned above, the onset of detectable flow instabilities also occurred earlier for backward-facing steps compared to forward-facing steps of comparable heights.

Studying the effects of steps can then lead to the investigation of the effects of rectangular or rounded humps on boundary layer transition, such as in the numerical simulations performed by Wörner et al. [WRW03]. In this study, the effect of humps could be described as a result of the juxtaposition of a forward-facing step followed by a backward-facing step. The effects of cylindrical roughness elements, such as wires studied by Klebanoff and Tidstrom [KT72] or Tani [Tan61], could therefore be expected to produce similar flow geometries. In particular, a comparison between the data from the experiments by Tani [Tan61] and Wang and Gaster [WG05] shows that wires will move transition location upstream for lower critical diameter-to-boundary-layer-thickness ratios $\left(h / \delta_{1}\right)$ than either forward- or backward-facing steps of comparable dimensions.

As shown in the literature, one of the main obstacles to commercial implementation of LFC is related to the sensitivity of the boundary layer to surface imperfections. Current manufacturing capabilities imply that the designs of boundary layer suction systems necessarily involve a surface discontinuity between the re- gions with and without suction. The purpose of this study is therefore to provide experimental data and analysis on the effects of one type of surface defect, namely two-dimensional positive roughness elements, on the laminar-turbulent transition of a sucked boundary layer. The research facility and flat plate are presented in the following section, followed by a characterization of the effects of boundary layer suction only (without surface defects) on transition. Finally, twodimensional positive surface defects (circular wires) are introduced on the flat plate wall and their effects are discussed.

\section{Experimental Method}

In this section, the subsonic wind tunnel facility along with the measurement techniques and experimental protocol used to acquire the steady aerodynamic data are presented. Further details about the facility and instrumentation can be found in Methel et al. [MVFC14].

\subsection{Research Facility}

This study was conducted in the ONERA TRIN 2 subsonic wind tunnel, shown in Figure 1, operating at local atmospheric conditions. Test section speeds range from $20 \mathrm{~m} . \mathrm{s}^{-1}$ to $50 \mathrm{~m} \cdot \mathrm{s}^{-1}$, corresponding to equivalent unit Reynolds numbers between $1 \cdot 10^{6} \mathrm{~m}^{-1}$ and $3 \cdot 10^{6} \mathrm{~m}^{-1}$. 

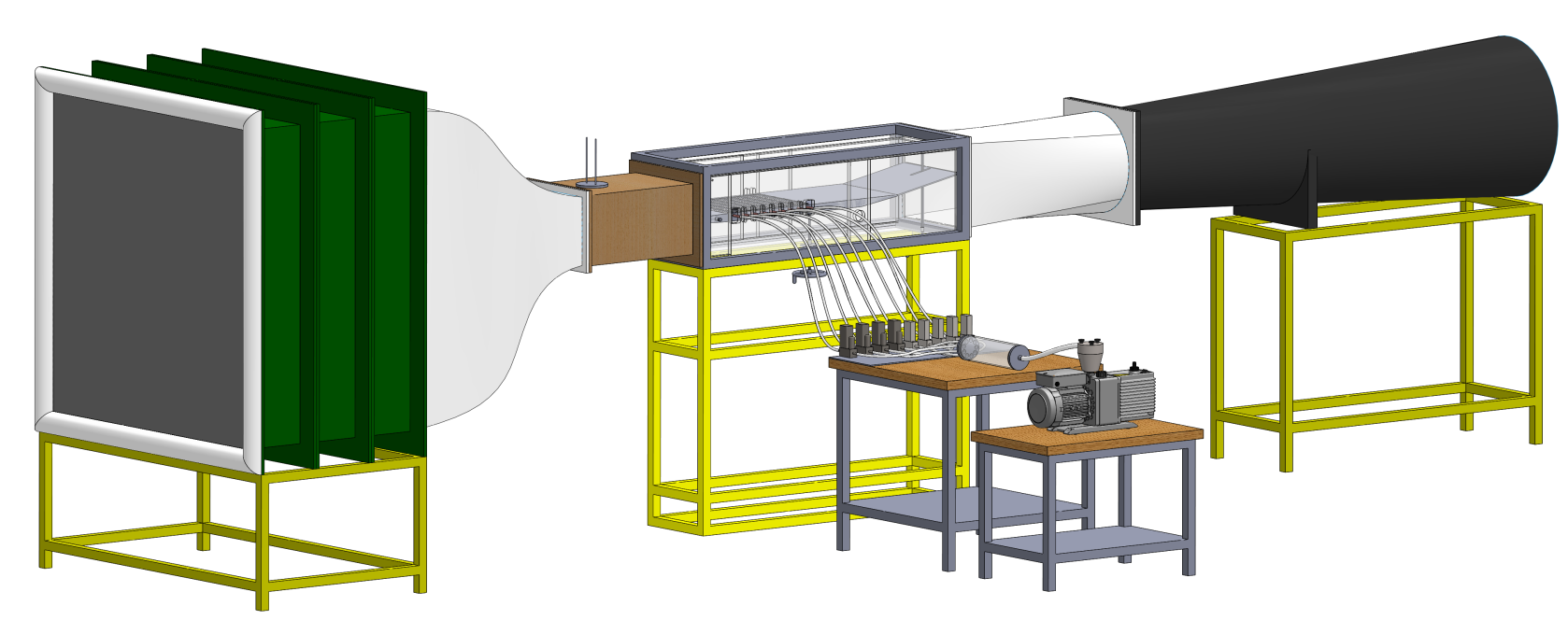

Fig. 1: Overview of the ONERA TRIN 2 subsonic wind tunnel facility

Atmospheric air is drawn in through four layers of screens in the settling chamber, to remove any particles and homogenize the flow, before being accelerated through a converging nozzle with an contraction ratio of 16. The test section has an entrance of dimensions $0.3 \mathrm{~m}$ by $0.4 \mathrm{~m}$ (height by width) and a total length of $1.5 \mathrm{~m}$. Test section speed and Reynolds number are determined with a Pitot-static tube and a total temperature probe located $0.15 \mathrm{~m}$ downstream of the test section entrance, and consequently $0.40 \mathrm{~m}$ upstream of the flat plate's leading edge.

Flow exits the test section through a diverging nozzle with an area ratio of 3 and is discharged in a noisereduction chamber (not shown in Figure 1). The purpose of this chamber is to prevent pressure waves from the driving fan (located downstream of the test section, at the wind tunnel exhaust) from propagating upstream into the test section. These waves could interfere with receptivity and modify the laminar-turbulent transition under study. All the walls, floor and ceiling of the noisereduction chamber are lined with foam and a partition obstructs the flow path between the diverging nozzle exit and the wind tunnel exhaust to create an additional obstacle to the upstream-travelling pressure waves from the fan.

The flat plate used for this experiment has a leading edge shape that was numerically optimized to minimize any suction peak on the working (upper) side, where measurements are acquired. The lower side is semi-elliptical while the upper side is defined by a thirdorder Béziers polynomial. Coordinates of the actual geometry are plotted in Figure 2(a) and specified in the Appendix. For ease of manufacturing, the leading edge is a separate component with an aluminum core and 
an epoxy shell. The main body of the flat plate is in aluminum, with a thickness of $0.035 \mathrm{~m}$ and spanning the entire width of the test section. The total length of the plate from leading to trailing edges is $1.10 \mathrm{~m}$.

The suction region starts $0.18 \mathrm{~m}$ from the leading edge and is divided in nine suction chambers, each $0.048 \mathrm{~m}$ (x) by $0.019 \mathrm{~m}(y)$ and separated by $0.002 \mathrm{~m}$ thick stringers resulting in a total streamwise length of $0.450 \mathrm{~m}$. Additionally, the chambers are $0.380 \mathrm{~m}(z)$ deep. A general layout of the flat plate with the suction region and the coordinate system is given in Figure 3. A $0.355 \mathrm{~m}$ flap is also mounted at the flat plate's trailing edge and its incidence can be adjusted independently from the flat plate's angle of attack. The purpose of the flap is to control the location of the stagnation point and the pressure distribution at the leading edge, e.g. to prevent any suction peak that can lead to an increase in instability amplification and result in earlier transition. The leading edge geometry and experimental pressure coefficient distribution for the chosen flat plate and flap angles of attack $\left(-0.08^{\circ}\right.$ and $-3.5^{\circ}$ respectively, negative angles being in the clockwise direction) are shown in Figure 2.

Inside each chamber, suction is distributed between four $2 \mathrm{~mm}$-diameter tubes of varying lengths along the spanwise $z$-direction. Additionally, a micro-perforated U-shaped metallic sheet is mounted over the four suc-

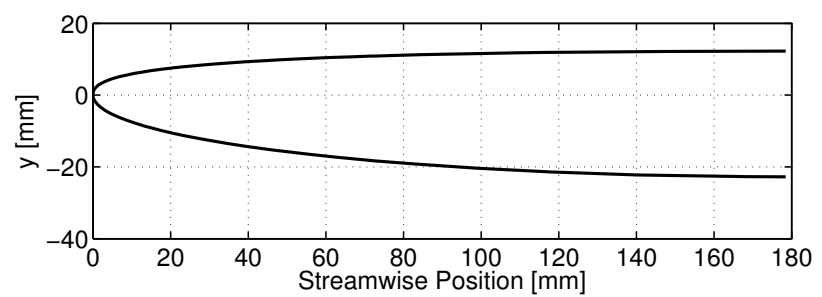

(a) Numerically optimized leading edge shape (coordinates given in Appendix)

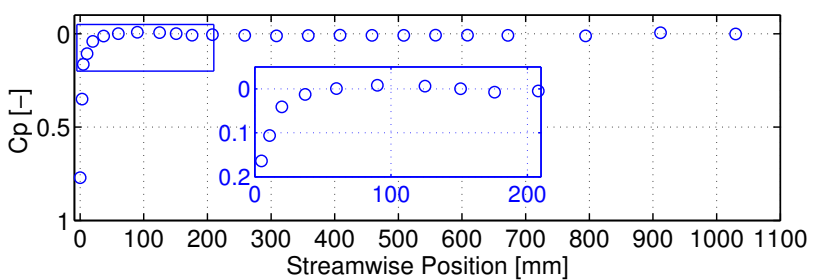

(b) Nominal pressure coefficient distribution along flat plate

Fig. 2: Leading edge geometry and resulting pressure coefficient distribution for chosen flat plate and flap angles of attack

tion tubes to further ensure uniform suction. Nine 10 mm-diameter tubes coming out of the side of the flat plate are connected to a manifold and ultimately the suction pump (shown in Figure 1).

\subsection{Instrumentation and Data Acquisition}

Static pressure ports are distributed along the entire chord of the flat plate at a spanwise location offset by $0.08 \mathrm{~m}$ from the centerline. Eleven ports are located in the leading edge region (i.e., upstream of the suction region), and four additional ports are located downstream of the suction region. Each suction chamber is also in- 


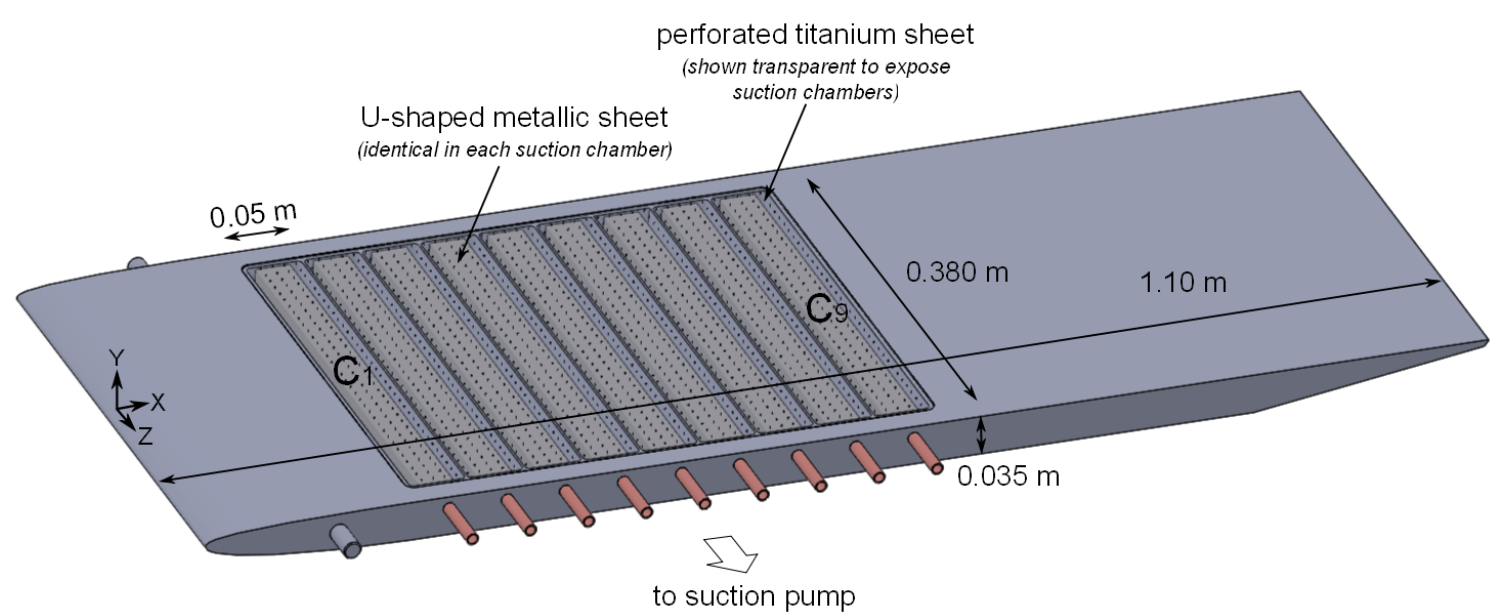

Fig. 3: General layout of the flat plate detailing the suction region

strumented with three static pressure ports across the span to check for uniform suction. The baseline flow condition at which all data were acquired (unless indicated, such as in the case of freestream turbulence measurements) corresponds to a Reynolds number equal to $2.6 \cdot 10^{6} \mathrm{~m}^{-1}$ (approximately $40 \mathrm{~m} \cdot \mathrm{s}^{-1}$ ).

Velocity measurements are acquired using a hotwire probe mounted on a two-dimensional traverse, with total travel of $0.710 \mathrm{~m}$ and $0.15 \mathrm{~m}$ in the $x$ - and $y$ directions respectively. For boundary layer investigations, flow velocity is measured by constant temperature hot-wire anemometry using a Dantec Streamline, a 90C10 CTA module and a 55P15 probe. At each of these data points, 400,000 samples were acquired at a frequency of $25 \mathrm{kHz}$. For turbulence intensity measurements, the $55 \mathrm{P} 15$ probe was replaced by a 55P11 model and 2 million samples were acquired at $25 \mathrm{kHz}$. Probes are calibrated in-situ at the beginning and completion of each test.

All test data are collected using a National Instruments CompactDAQ-9178 with two NI-9215 modules for voltage measurements and an NI-9211 module for temperature readings. Anemometer data are recorded as raw output from the Dantec Streamline (with low-pass filtering for anti-aliasing), as well as a processed signal after $\mathrm{A} / \mathrm{C}$ coupling, low-pass filtering and amplification by a gain of 10 with a Krohn-Hite 3905C filter/amplifier. Cut-off frequency and sampling rate are set so as to satisfy the Nyquist-Shannon theorem.

The transition location is determined using the Root Mean Square (RMS) values of the anemometer's ACcomponent after filtering, amplification and conversion to velocity units. Velocity fluctuations inside the boundary layer, that are small and relatively constant in lam- 
inar flow, start to increase when transition is triggered, reaching a maximum value before settling back down to a new constant value for turbulent flow. As a note, fluctuation levels in the turbulent regime are higher than in the laminar regime. In this study, the location of the onset of transition is identified by the abscissa where velocity fluctuations first begin to increase at a rate equal or superior to $2 \cdot 10^{-4}\left[u^{\prime} / U_{\infty}\right] \cdot \mathrm{mm}^{-1}$, and after which fluctuations continue to increase. As an example, velocity fluctuations in Figure 6 indicate that the onset of transition for the $0 \%$ porosity case is located $740 \mathrm{~mm}$ from the leading edge.

Finally, mass flow rate in each suction chamber is monitored and controlled using Brooks SLA5850 and Bronkhorst F201 thermal mass flow meters with control valves.

2.3 Protocol and Validation of a Laminar-to-Turbulent Transition Experiment

As mentioned previously, the flow physics involved in laminar-turbulent transition is sensitive to small external disturbances, and experiments have to be carefully monitored to prevent foreign disturbances from interfering with measurements. Guidelines suggested by Saric [Sar08] and Hunt et al. $\left[\mathrm{HDK}^{+} 10\right]$ for conducting rigorous transition experiments were integrated in the present study and are briefly presented in this section. One of the purpose of the experimental results from this investigation is to be used as validation data for numerical models under development. To facilitate such comparison, the simplest flow condition to simulate was chosen. Flat plate and flap angles of attack were set for a zero pressure gradient over the entire plate's chord (excluding the leading edge region) to obtain Blasius flow on the upper side. Given the relatively low freestream turbulence of the wind tunnel coupled to the flat plate with zero pressure gradient, the traditional path to transition, as defined by Morkovin et al. [MRH94], is expected to occur as a result of the linear amplification of Tollmien-Schlichting (TS) waves.

The evolution of boundary layer parameters for the no suction configuration with a solid wall (i.e., no porosity) was calculated for a flow over the same flat plate geometry and with the pressure gradient shown in Figure 2(b), using ONERA's in-house boundary layer code. These numerical results were compared to experimental data, as shown in Figure 4. Good agreement is found between the numerical and experimental data for all boundary layer integral values. Additionally, both numerical and experimental shape factors values are close to 2.59 over the flat plate region, confirming the presence of Blasius flow for the baseline no suction and no porosity case.

Figure 5(c) is an example of a power spectral density distribution (PSD) of the velocity fluctuations at 


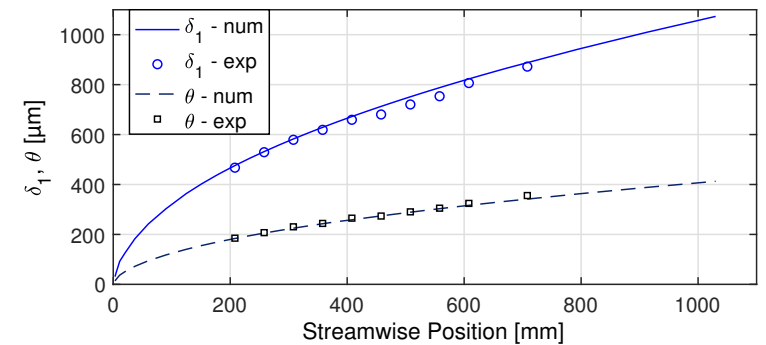

(a) Displacement thickness $\delta_{1}$ and momentum thickness $\theta$ evolution

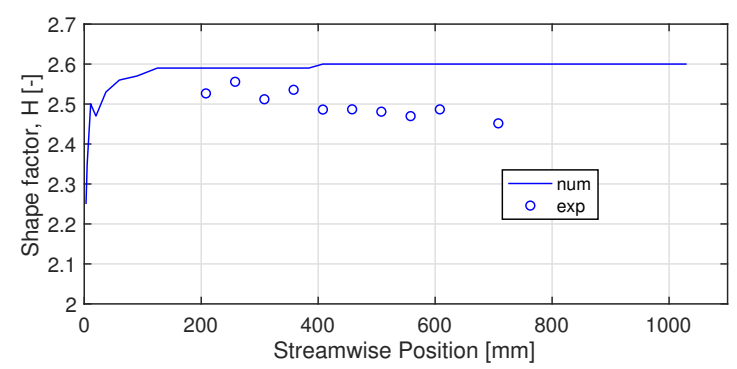

(b) Shape Factor evolution

Fig. 4: Integral values of the boundary for the solid wall (no porosity) flat plate

an altitude inside the boundary layer of approximately $400 \mu m$ from the wall and for a streamwise position 508 mm from the leading edge at operating Reynolds number $2.6 \cdot 10^{6}\left(\sim 40 \mathrm{~m} \cdot \mathrm{s}^{-1}\right)$. Since this position is upstream of the transition location $x_{T}$ at $740 \mathrm{~mm}$, TS waves are sufficiently amplified so as to be identified by the bulge in the PSD over the frequencies ranging from $400 \mathrm{~Hz}$ to $1 \mathrm{kHz}$, with a peak close to $610 \mathrm{~Hz}$. Linear stability analysis, using an ONERA in-house code based on the Orr-Sommerfeld equation, was also performed on the Blasius profile and revealed that the most amplified frequency responsible for transition was also between
$600 \mathrm{~Hz}$ and $650 \mathrm{~Hz}$.

The unsteady data to evaluate PSDs are available for all altitudes inside the boundary layer. Integrating the PSD of each altitude over the narrow range of frequencies between $592 \mathrm{~Hz}$ and $632 \mathrm{~Hz}$ results in a profile of TS amplitudes at $x$ equal to $558 \mathrm{~mm}$ and around an approximate frequency of $610 \mathrm{~Hz}$. Using the Blasius profile scaled to the corresponding $\delta_{1}$ and $U_{e}$ of the closest available streamwise position $(508 \mathrm{~mm})$, the corresponding TS-amplitude profile for frequency $600 \mathrm{~Hz}$ was evaluated using linear stability theory (LST) and compared to experimental data in Figure 5(b). Good agreement is found between theory and experiment, confirming that laminar-turbulent transition is driven by TS instabilities. This result also suggests that streamwise traverses inside the boundary layer at a constant altitude of $300 \mu \mathrm{m}$ from the wall are relevant for detecting the start of transition (such as in Figure 6), since the TS $u^{\prime}$ amplitude is maximum close to that region.

\section{Effects from Porous Wall and Wall Suction}

\section{on Boundary Layer Transition}

Even in the absence of wall suction, the porosity of the wall through which suction is to be performed was found to have an effect on boundary layer transition. In this section the suction panels with different porosities are first described along with the overall suction sys- 

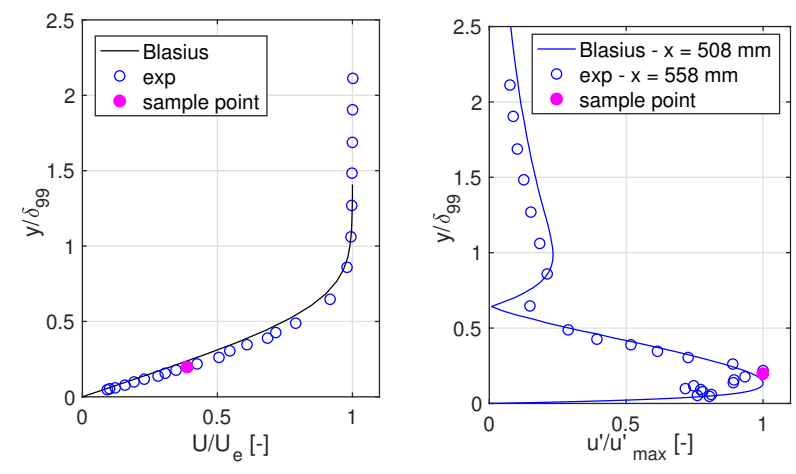

(a) Normalized boundary

(b) TS-amplitude profile layer profile $(x=558 \mathrm{~mm}) \quad$ comparison

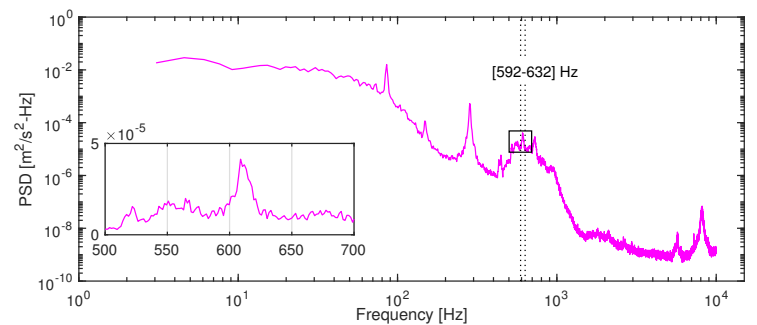

(c) PSD inside boundary layer at the sample point $(558 \mathrm{~mm}$ $400 \mu \mathrm{m})$ where $u^{\prime}$ is maximum with integration range

Fig. 5: Identification of $\sim 600 \mathrm{~Hz}$ TS profile at $x=558$ $\mathrm{mm}\left(\delta_{99}=2.43 \mathrm{~mm}\right)$ and $\operatorname{Re}=2.6 \cdot 10^{6}\left(\sim 40 \mathrm{~m} \cdot \mathrm{s}^{-1}\right)$

tem. Observations on the effect of porosity on laminarturbulent transition are then briefly described. Finally the effects of boundary layer suction on the boundary layer transition without any surface defects are characterized.

\subsection{Wall Suction Parameters}

The suction panels with porosity consist of $0.9 \mathrm{~mm}-$ thick micro-perforated titanium sheets, while the panel without porosity is made of $0.8 \mathrm{~mm}$-thick aluminum.
Table 1: Transition positions for all suction cases with respect to the different panel porosities

\begin{tabular}{cccc}
\hline Suction panel & $p[\%]$ & Hole diameter $[\mu \mathrm{m}]$ & Hole spacing $[\mathrm{mm}]$ \\
\hline P1 & 0 & 0 & 0 \\
P2 & 0.26 & 90 & 1.6 \\
P3 & 1.34 & 190 & 1.44 \\
\hline
\end{tabular}

All are flush-mounted with the rest of the flat plate's upper side. The three suction panels that were tested for this study have porosities $p$ of $0 \%$ (solid wall), $0.26 \%$, and $1.34 \%$, with porosity defined as the ratio of the holes' area to the sheet's total surface area.

The panel with $0.26 \%$ porosity has $90 \mu m$-diameter holes evenly spaced in a square pattern of dimensions $1.6 \mathrm{~mm}$ by $1.6 \mathrm{~mm}$. The panel with $1.34 \%$ porosity has $190 \mu \mathrm{m}$-diameter holes evenly spaced in a square pattern of dimensions $1.44 \mathrm{~mm}$ by $1.44 \mathrm{~mm}$. A summary of the different suction panels along with their labels is given in Table 1. Suction panels were labeled P1, P2 or P3 to leave the possibility open for either porosity and/or hole diameter to be responsible for the effect on transition.

Copper tubes protrude from one side of the flat plate to connect each suction chamber to its appropriate mass flow meter. Downstream of the flow meters, all flows are discharged in a manifold, whose exhaust is connected to the vacuum pump. For all test configurations with suction, total mass flow rate of the suction flow was 
kept constant at 0.4 g.s ${ }^{-1}$ and only suction distribution varied.

Based on results from Juillen et al. [JCA95] and data from the present study, four test configurations were chosen: no suction, 0.4 g.s ${ }^{-1}$ suction on chamber 1 only, 0.2 g.s s $^{-1}$ suction on chambers 3 and 5 , and 0.044 g.s ${ }^{-1}$ suction on each of the nine chambers that will respectively be referred to as no suction, C1/0.400, C3,5/0.200, and full suction.

\subsection{Porous Wall Effects on Transition Location}

The transition positions for the different suction panel porosities without suction can be compared by means of the streamwise evolution of the velocity fluctuations $u$ ', as shown in Figure 6 . In this case, the configuration P3 has the position of the onset of transition closest to the leading edge $\left(x_{T}=510 \mathrm{~mm}, R e_{x T}=1.33 \cdot 10^{6}\right)$, whereas the case P1 (corresponding to the "classic" flat plate) has the transition position furthest from the leading edge $\left(x_{T}=740 \mathrm{~mm}, R e_{x T}=1.92 \cdot 10^{6}\right)$. The case P2 has an intermediate transition location $\left(x_{T}=640 \mathrm{~mm}\right.$, $\left.R e_{x T}=1.66 \cdot 10^{6}\right)$. A porous wall through which no suction is being applied therefore seems to destabilize the boundary layer.

To verify that the destabilizing effect observed for porous walls was not related to surface roughness issues, the perforations were obstructed with tape on the lower side (i.e., the side not in contact with the main outer flow) of the suction panels P2 and P3. As shown on Figure 6 , once the porosity of the suction panel is removed, the transition location matches that of the flat plate with no porosity, indicating that the surface roughness of the perforations are not responsible for destabilizing the boundary layer. These results corroborate the findings from numerical studies mentioned previously ([Cho94],[TC15],[CP01]).

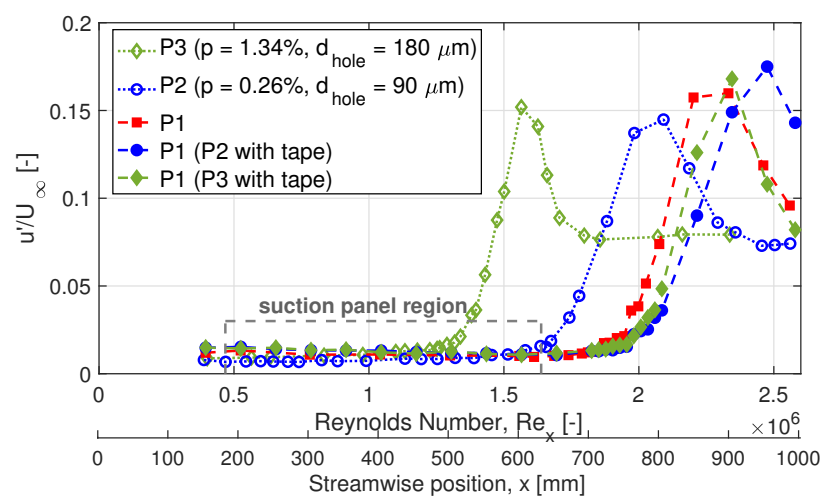

Fig. 6: Streamwise velocity fluctuations for all tested cases of porosity

3.3 Wall Suction Effects on Boundary Layer Mean

Flow and Transition

For the remainder of the study, the nine suction chambers are sealed with the micro-perforated sheet with $0.26 \%$ porosity. Results with the $1.34 \%$ porosity panel can be assumed to be qualitatively similar if no difference is mentioned or shown. 
Laminar Flow Control using suction stabilizes the boundary layer by increasing the curvature of the mean velocity profile, thereby making it "fuller". According to linear stability theory, a fuller profile is more stable and has lower disturbance growth (Reed et al. [RSA96]).

For all suction configurations, boundary layer profiles were acquired at three streamwise positions of interest: over the first suction chamber $\mathrm{C} 1(x=208 \mathrm{~mm})$, over the last suction chamber C9 $(x=608 \mathrm{~mm})$ and close to the flat plate trailing edge $(x=950 \mathrm{~mm})$. The results are shown in Figure 7 with velocity measurement uncertainties within symbol size.

At both streamwise locations over suction chambers C1 and C9, boundary layer profiles for all suction configurations reveal that flow is laminar. In particular, over chamber $\mathrm{C} 1$, shown in Figure $7(\mathrm{a})$, the profiles for cases no suction and C3,5/0.200 correspond, as expected, to the solution of a Blasius profile since no suction is locally being applied over this chamber. On the other hand, the boundary layer for case $\mathrm{C} 1 / 0.400$ has a slightly fuller profile due to the local effect of wall suction. In the full suction case, despite the presence of wall suction, the profile is close to a Blasius profile because suction velocity is so weak. The effect of suction for the full suction configuration is therefore not detectable in terms of the mean velocity profile.

Over chamber C9, profiles C1/0.400 and C3,5/0.200 have both recovered the same shape as the no suction profile, as seen in Figure 7(b). The effect of suction on the mean velocity profile is therefore local. For this reason and because of the weak suction velocities, the full suction profile is still close to the Blasius solution. Close to the trailing edge $(x=950 \mathrm{~mm}$, Figure 7(c)), the no suction configuration is fully turbulent. On the other hand, although boundary layers for C1/0.400, C3,5/0.200 and full suction are undergoing transition at this location, the mean velocity profiles do not yet reflect that event.

Transition location for all configurations with suction was moved further downstream than in the case without suction, as recorded in Table 2. The suction distribution proved to be a parameter of influence: for the same mass flow rate, suction distributed over chambers C3 and C5 simultaneously or over all chambers delayed transition more effectively than suction over chamber $\mathrm{C} 1$ only. In this experiment on a flat plate, the boundary layer evolves spatially in the streamwise direction: depending on the chamber, suction is applied to a boundary layer with instabilities at different stages of amplification. Although having lower local suction velocities than $\mathrm{C} 1 / 0.400$, the $\mathrm{C} 3,5 / 0.200$ and full suction configurations seem to act over areas that have a strong influence on boundary layer stability, which results in identical transition positions. Additionally, the effect of 


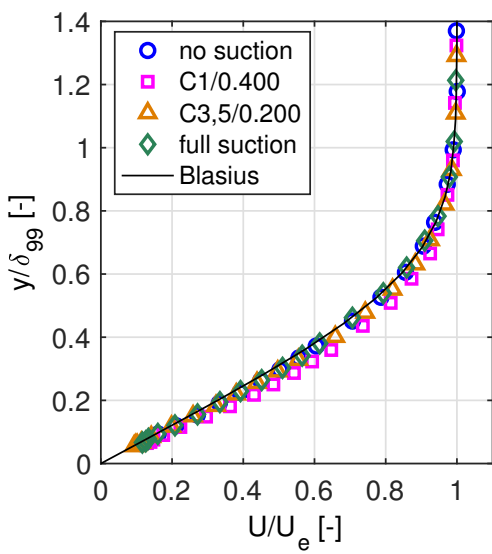

(a) $\operatorname{Re}_{\mathrm{x}}=5.3 \cdot 10^{5}(\mathrm{x} \sim 208 \mathrm{~mm})$

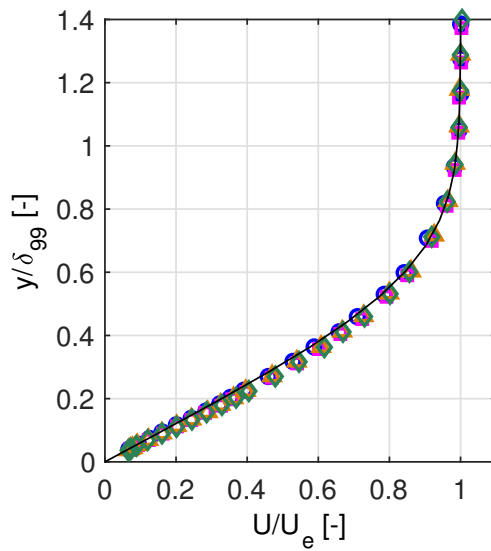

(b) $\operatorname{Re}_{\mathrm{x}}=1.6 \cdot 10^{6}(\mathrm{x} \sim 608 \mathrm{~mm})$

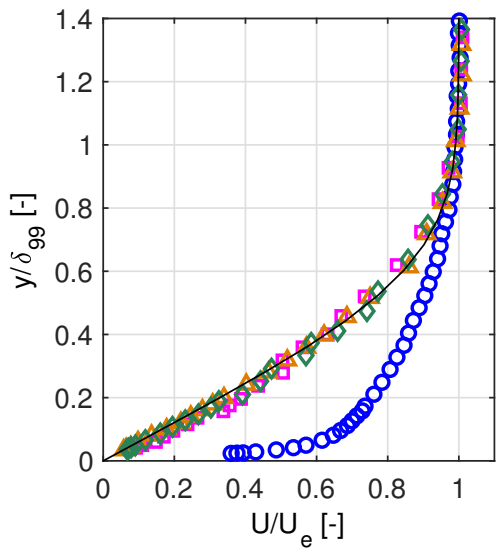

(c) $\operatorname{Re}_{\mathrm{x}}=2.5 \cdot 10^{6}(\mathrm{x} \sim 950 \mathrm{~mm})$

Fig. 7: Boundary layer profiles along different streamwise positions for all suction configurations

Table 2: Transition positions for all suction cases with respect to the different panel porosities

$p=0.26 \% \quad p=1.34 \% \quad p=0 \%$

\begin{tabular}{lcccc} 
suction case & $\mathrm{x}_{\mathrm{T}}[\mathrm{mm}]$ & $\mathrm{Re}_{\mathrm{xT}}[-]$ & $R e_{x T}[-]$ & $R e_{x T}[-]$ \\
\hline no suction & 640 & $1.66 \cdot 10^{6}$ & $1.33 \cdot 10^{6}$ & $1.92 \cdot 10^{6}$ \\
$\mathrm{C} 1 / 0.400$ & 850 & $2.20 \cdot 10^{6}$ & $1.56 \cdot 10^{6}$ & $\mathrm{~N} / \mathrm{A}$ \\
$\mathrm{C} 3,5 / 0.200$ & 890 & $2.30 \cdot 10^{6}$ & $1.66 \cdot 10^{6}$ & $\mathrm{~N} / \mathrm{A}$ \\
full suction & 890 & $2.30 \cdot 10^{6}$ & $1.59 \cdot 10^{6}$ & $\mathrm{~N} / \mathrm{A}$ \\
\hline
\end{tabular}

the full suction case, which was not visible on any of the mean velocity profiles, can clearly be observed on the transition location.

\section{Effects of Positive Surface Defects on}

\section{Boundary Layer Transition with Wall Suction}

This section first describes the geometry of the surface defects and their installation on the flat plate. Their effects on boundary layer stability in cases with and without suction are then discussed.

\subsection{Surface Defect Geometry and Installation}

Cylindrical spanwise roughness elements (wires) were chosen for their single degree of freedom (diameter, $h)$ and their ease of installation. This type of surface imperfection is not characteristic of defects found on aerodynamic surfaces; however, the following test cases represent a first proof-of-concept of the experimental set-up's capacity to study the combined effects of wall suction and surface imperfections on boundary layer transition. Additionnally, results from this paper extend previous studies ([KT72], [Tan61]) on a similar type of surface defects. The choice in wire diameters was based on relative height with respect to the local boundary layer displacement thickness $\delta_{1}$ calculated with- 
out suction. Diameter-to-displacement thickness ratios $h / \delta_{1}$ averaging around $0.2,0.4,0.5$ and 0.6 were tested. For a given set of wire diameter $h$ and ratio $h / \delta_{1}$, the position of the wire was defined as the location, at a junction between two chambers, where displacement thickness $\delta_{1}$ for the no suction case reached the closest appropriate value. Ratio values $h / \delta_{1}$ are given as averaged approximations because surface defect positions were not changed with suction configuration, thereby not accounting for the change in local displacement thickness. A summary of surface defect geometry and positions is given in Table 3. Additionally, the local boundary layer thickness at the corresponding surface defect locations are presented in Table 4, along with the no suction $h / \delta_{1}$ and the rounded average $h / \delta_{1}$ that will also be used to reference the different cases. Finally, wires were adhered to the flat plate using spray glue applied directly to the defect so as to minimize additional thickness due to mounting and local blockage on the perforated sheet.

\subsection{Effects of Surface Defects on Mean Flow and}

Transition

Mean velocity profiles at a position one millimeter downstream of the surface defect were acquired for the different relative height ratios $h / \delta_{1}$ and are shown in Figure 8 . In all cases but one (case $i v, \mathrm{C} 1 / 0.400)$, suc-
Table 3: Summary of the surface defect (SD) geometry and position

\begin{tabular}{|c|c|c|c|}
\hline case & $\begin{array}{c}\text { wire } \\
\text { diameter, } \\
\mathrm{h}[\mu \mathrm{m}]\end{array}$ & $\begin{array}{l}\mathrm{x}_{\mathrm{SD}}[\mathrm{mm}] \\
\left(R e_{x, S D} \cdot 10^{-6}\right)\end{array}$ & Note on $\mathrm{x}_{\mathrm{SD}}$ \\
\hline $\mathrm{i}$ & 100 & $333(0.87)$ & $\begin{array}{l}\text { located at junction of } \\
\text { C3 and C4 }\end{array}$ \\
\hline ii & 300 & $636(1.65)$ & $\begin{array}{l}\text { located immediately } \\
\text { downstream of C9 }\end{array}$ \\
\hline iii & 300 & $434(1.13)$ & $\begin{array}{l}\text { located at junction of } \\
\text { C5 and C6 }\end{array}$ \\
\hline iv & 300 & $234(0.61)$ & $\begin{array}{l}\text { located at junction of } \\
\mathrm{C} 1 \text { and } \mathrm{C} 2\end{array}$ \\
\hline
\end{tabular}

Table 4: Local boundary layer thickness (numerical value) at surface defect location

\begin{tabular}{|c|c|c|c|c|c|c|}
\hline \multirow[b]{2}{*}{ case } & \multicolumn{4}{|c|}{$\delta_{1}[\mu m]$ at $x_{S D}($ from $3 C 3 D)$} & & \\
\hline & $\begin{array}{l}\text { no } \\
\text { suc- } \\
\text { tion }\end{array}$ & $\begin{array}{c}\text { C1/ } \\
0.400\end{array}$ & $\begin{array}{l}\text { C3,5/ } \\
0.200\end{array}$ & $\begin{array}{l}\text { full } \\
\text { suc- } \\
\text { tion }\end{array}$ & $\begin{array}{c}n o \\
\text { suc- } \\
\text { tion } \\
h / \delta_{1}\end{array}$ & $\begin{array}{l}\sim \text { mean } \\
\left(h / \delta_{1}\right) \\
\text { (for ref- } \\
\text { erence) }\end{array}$ \\
\hline$i$ & 605 & 569 & 547 & 585 & 0.17 & $\sim 0.2$ \\
\hline$i i$ & 839 & 819 & 804 & 793 & 0.36 & $\sim 0.4$ \\
\hline$i i i$ & 692 & 665 & 611 & 663 & 0.43 & $\sim 0.5$ \\
\hline$i v$ & 506 & 421 & 506 & 496 & 0.59 & $\sim 0.6$ \\
\hline
\end{tabular}

tion configuration does not affect boundary layer profile: just downstream of the surface defect, the effect of the wire is stronger than the effect of wall suction.

In cases $i$ and $i i$, i.e., for $h / \delta_{1}$ values $\sim 0.2$ and $\sim 0.4$, 
Table 5: $R e_{x T}$ for suction panel $p=0.26 \%$

\begin{tabular}{|c|c|c|c|}
\hline$h / \delta_{1}$ & no defect & $\sim 0.2$ & $\sim 0.4$ \\
\hline no suction & $1.66 \cdot 10^{6}$ & $1.59 \cdot 10^{6}$ & $1.66 \cdot 10^{6}$ \\
\hline $\mathrm{C} 1 / 0.400$ & $2.24 \cdot 10^{6}$ & $2.05 \cdot 10^{6}$ & $2.04 \cdot 10^{6}$ \\
\hline $\mathrm{C} 3,5 / 0.200$ & $2.30 \cdot 10^{6}$ & $2.21 \cdot 10^{6}$ & $2.20 \cdot 10^{6}$ \\
\hline full suction & $2.30 \cdot 10^{6}$ & $2.24 \cdot 10^{6}$ & $2.20 \cdot 10^{6}$ \\
\hline
\end{tabular}

only a slight profile inflection is induced by the surface defect. In general, for these cases, all configurations with suction still transition further downstream than when no suction is applied. Additionally, even in the presence of these surface defects, the varying effectiveness of the suction configurations is apparent from the results shown in Table 5: transitions locations are simply shifted upstream but keep the same relative position with respect to each other. For instance, the table shows that C3,5/0.200 and full suction transition at the same shifted location, while $\mathrm{C} 1 / 0.400$ is still less effective and transitions earlier. Therefore, despite the similar mean velocity profiles immediately downstream of the surface defect, stabilization due to suction still proves effective. Nevertheless, as the surface defect's $h / \delta_{1}$ increases from $\sim 0.2$ to $\sim 0.4$, the effectiveness of wall suction tends to weaken slightly. The corresponding results for suction panels with no porosity and with $1.34 \%$ porosity are given in Tables 8 and 9 respectively of the Appendix.
This trend is confirmed through cases $i i i$ and $i v$, where $h / \delta_{1}$ increases to $\sim 0.5$ and $\sim 0.6$. Regardless of suction configuration, transition now occurs at the same position: the location of the surface defect. The corresponding mean velocity profiles for all suction configurations display well-defined inflection points, shown in Figures $8(\mathrm{c})$ and $8(\mathrm{~d})$. As the $h / \delta_{1}$ ratio is raised between cases $i i i$ and $i v$, the proportion of the boundary layer disrupted by the surface defect is consequently larger, which explains the increase in the altitude of the inflection point. Therefore, as the inflection point is further from the wall, the profile becomes more unstable (which is also similar to the findings related to the effects of an adverse pressure gradient on boundary layer stability in [Mac77]), and wall suction becomes less effective. In these cases, the instability caused by the wire could not be cancelled or lowered by any of the suction configurations and transition therefore occurs at the location of the surface defect.

As mentioned at the beginning of this section, Figure $8(d)$, for case $i v$, exhibits one anomaly: the $\mathrm{C} 1 / 0.400$ profile, which has an inflection point at a higher altitude than the profiles from the other suction configurations. In this case, the surface defect is mounted immediately downstream of suction chamber $\mathrm{C} 1$, on which maximum suction flow rate is being applied. Through the action of wall suction, the $\mathrm{C} 1 / 0.400$ boundary layer at the surface 


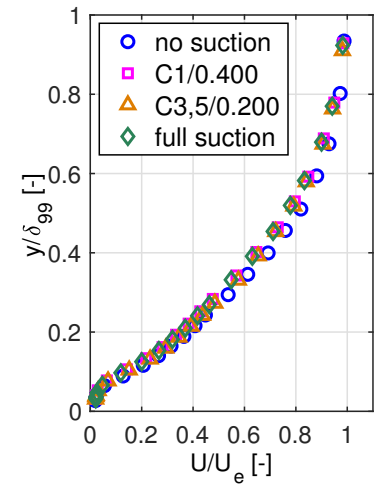

(a) case $i\left(h / \delta_{1} \sim 0.2\right)$

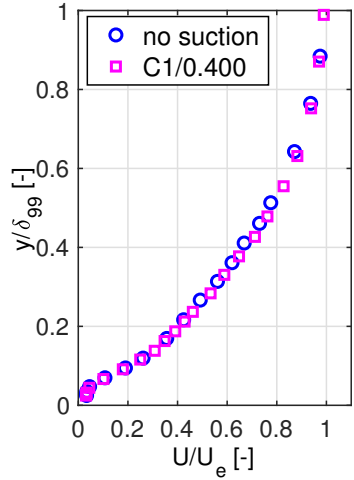

(b) case $i i\left(h / \delta_{1} \sim 0.4\right)$

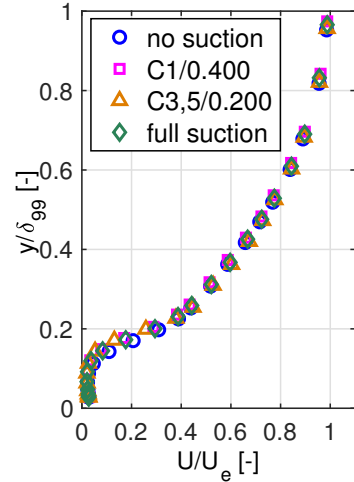

(c) case iii $\left(h / \delta_{1} \sim 0.5\right)$

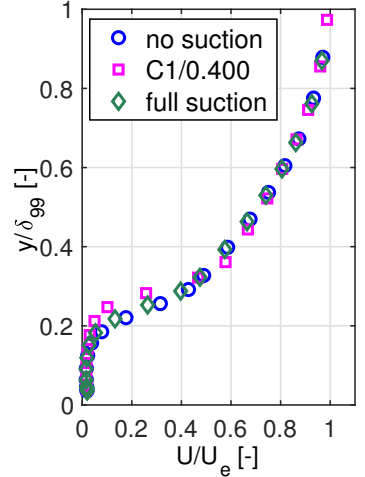

(d) case $i v\left(h / \delta_{1} \sim 0.6\right)$

Fig. 8: Boundary layer profiles $1 \mathrm{~mm}$ downstream of the surface defect position for different suction configurations

defect location is therefore noticeably thinner than in configurations no suction or full suction (respectively, $\Delta \delta_{1}=85 \mu \mathrm{m}$ and $\Delta \delta_{1}=75 \mu \mathrm{m}$ using the 3C3D boundary layer code, see Table 4). With this lower displacement thickness, $h / \delta_{1}$ for $\mathrm{C} 1 / 0.400$ is actually closer to 0.7 than 0.6. In the previous paragraph, when the size of the surface defect with respect to displacement thickness increased, the altitude of the inflection point inside the boundary layer was raised. The anomaly of the $\mathrm{C} 1 / 0.400$ profile discussed here is therefore a direct consequence of the reduced boundary layer thickness due to wall suction. Although this anomaly could have been avoided by placing the profile in its own distinct category, this situation was a more vivid illustration of the competing effects between wall suction and surface defects. Translated to a more practical LFC situation for instance, a surface defect remaining at the same position would affect boundary layer stability differently depending on the local suction distribution.

For each suction configuration, the transition Reynolds number with and without a surface defect is compared in Figure 9(a) to data from Tani [Tan61] and Feindt [Fei56] where the effects of circular wires on transition were investigated. Since the reference case with no suction and no surface defect for the present data has an absolute transition position $\operatorname{Re}_{\mathrm{x} T}$ close to Tani's equivalent case, no attempt to normalize the data in Figure 9(a) to account for potential differences between wind tunnels or experimental set-ups was performed.

In general, the data in the present study show relatively good agreement with Tani's data, especially for the no suction case where comparison is most relevant. The trend for the configurations with suction, although similar to the one without suction, is exacerbated. For the given two-dimensional positive surface defects in this study, wall suction is therefore only effective up to crit- 
ical relative heights similar to those of a configuration without suction. In particular, the effect of wall suction or wall porosity can be paralleled to the effect of freestream turbulence $T u$, as shown by the data from Feindt. Whether transition location is moved further downstream through the effect of lower freestream turbulence or boundary layer suction, transition Reynolds number is nearly independent of the surface defect's relative height up to values of $h / \delta_{1}$ between 0.3 and 0.4. However, above their respective critical $h / \delta_{1}$ ratio, all data sets seem to collapse to Tani's original curve, since neither freestream turbulence nor wall suction can counteract the boundary layer destabilization induced by the surface defect.

To compare the behavior of the different suction configurations and porosities to surface defects with similar values of $h / \delta_{1}$, a non-dimensional parameter $\Delta_{x T, S D}$ was then introduced in Figure 9(b) and is defined as:

$\Delta_{x T, S D}=\frac{R e_{x T, S D}-R e_{x, S D}}{R e_{x T, n o S D}-R e_{x, S D}}$

Variables $R e_{x T, S D}$ and $R e_{x T, n o S D}$ correspond to the transition Reynolds number with and without a surface defect for a given porosity and suction configuration and $R e_{x, S D}$ corresponds to the location of the surface defect. The parameter $\Delta_{x T, S D}$ is therefore a mea-

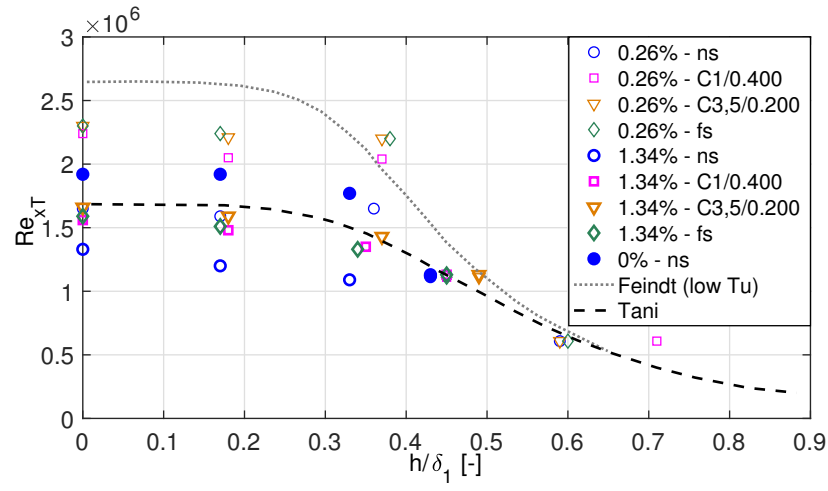

(a) Transition Reynolds Number, $\operatorname{Re}_{\mathrm{x} T}$

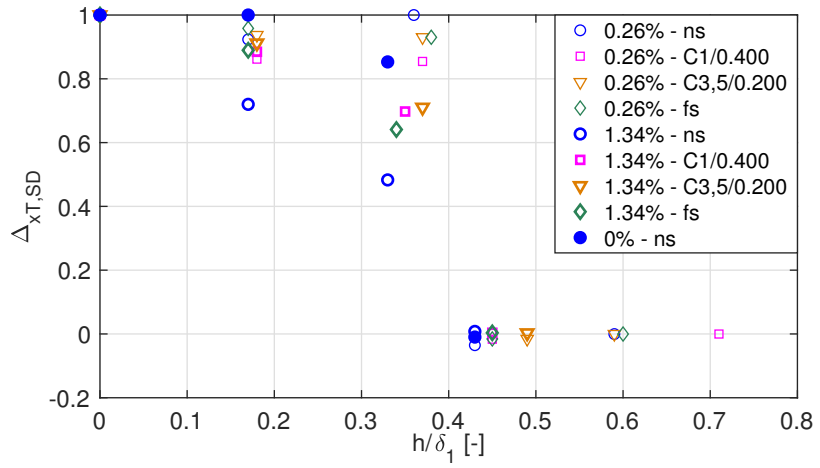

(b) Transition $\Delta_{\mathrm{xT}, \mathrm{SD}}$

Fig. 9: Transition parameters variation with respect to relative roughness height for all suction configurations

sure of the relative change in transition position due to the presence of a surface defect, using the roughness element position as the reference. When $\Delta_{x T, S D}$ is equal to 1 , the surface defect has no effect on transition whereas when $\Delta_{x T, S D}$ is equal to zero, transition occurs at the location of the surface defect. Figure 9(b) thus shows that regardless of the porosity or suction configuration, the critical $h / \delta_{1}$ seems to be the same, at an approximate value of 0.4 . In the case of porosity equal to $0.26 \%$, the cases with suction seem more sensitive to 
the presence of a surface defect than without suction since they depart from 1 more significantly before the critical $h / \delta_{1}$. On the other hand, in the case of porosity equal to $1.34 \%$, the no suction case is more sensitive to surface defects than the cases with suction and decreases more rapidly to zero before the critical $h / \delta_{1}$. Overall, between the two porous cases, the panel with higher porosity seems more sensitive to surface defects that with lower porosity. This difference could, in part, be explained by the varying lengths of the laminar flow regions depending on the case, suggesting that for the same surface defect position, the boundary layer is actually at a different phase of its evolution. Differences between the two porosities will not be discussed further, being beyond the scope of this study.

\subsection{Effect of Surface Defects on Boundary Layer Stability: Spectral Analysis}

The effect of surface defects on transition can also be evaluated through spectral analysis using unsteady data from streamwise traverses at $300 \mu m$ from the wall. Figure 13 shows the PSD of the velocity fluctuations for each suction configuration at the traverse position closest to its corresponding transition Reynolds number, i.e., where instabilities responsible for transition can be observed by their noticeably larger magnitudes. In the case with neither suction nor surface defect, shown by the thick blue line in Figure 10(a), a bulge ranging from $500 \mathrm{~Hz}$ to $700 \mathrm{~Hz}$ can be noticed. This bulge corresponds to the TS waves responsible for the onset of transition as discussed in Section 2.3. Similarly, the cases with suction (represented by the medium magenta line for $\mathrm{C} 1 / 0.400$ and the thin green line for full suction) also have a bulge over the same frequency range with, however, lower amplitude and at positions further downstream. Suction therefore does not seem to change the mechanisms through which transition occurs but rather delays and reduces the amplification of the natural (TS) instabilities. As a note, configuration C3,5/0.200 is not shown to improve general clarity of the graphs and because its spectra are similar to the full suction case.

In cases $i$ and $i i$, shown in Figures 10(b) and 10(c), where a surface defect is present but transition is simply shifted upstream, the general shape of the curves and the values of the PSD amplitudes reached by the TS instabilities are similar to the ones found for the no suction case. This seems to indicate that the mechanisms leading to transition are unchanged but that, in this case, the presence of the surface defect slightly increased the amplification process of the TS waves.

However, in cases $i i i$ and $i v$, where transition occurs very close to the location of the surface defect, the general shape of the curves, in Figures 10(d) and 10(e) re- 
spectively, has changed. A new bulge, covering a wide range of high frequencies from $1.5 \mathrm{kHz}$ to $5 \mathrm{kHz}$ for case iii and $3 \mathrm{kHz}$ to $10 \mathrm{kHz}$ for case $i v$, has now clearly appeared. This phenomena is similar to the one described by Mack [Mac77] and observed by Watanabe and Kobayashi [WK91] who also studied the effect of wires on transition.

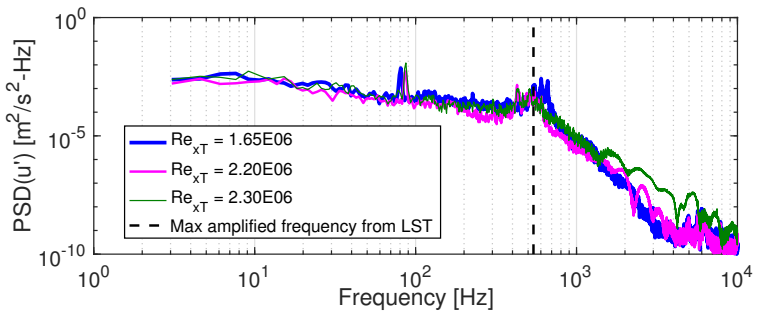

(a) no defect

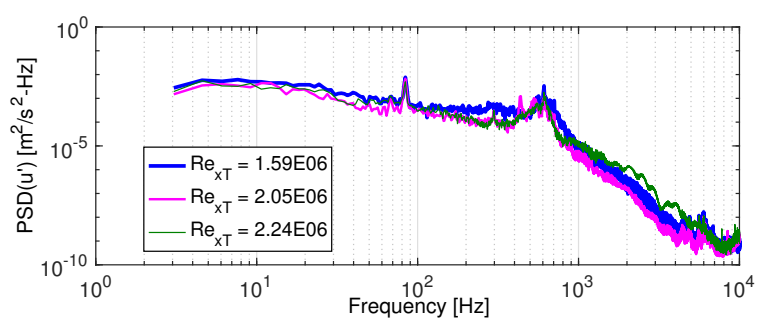

(b) case $i\left(h / \delta_{1} \sim 0.2\right)$

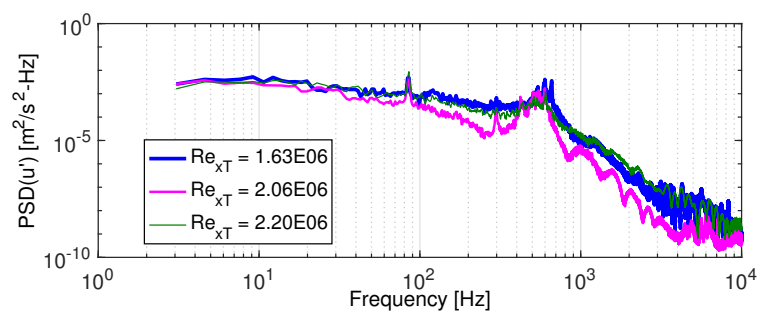

(c) case $i i\left(h / \delta_{1} \sim 0.4\right)$

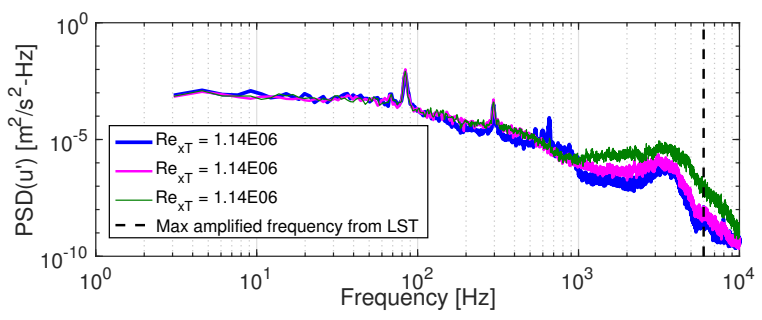

(d) case $i i i\left(h / \delta_{1} \sim 0.5\right)$

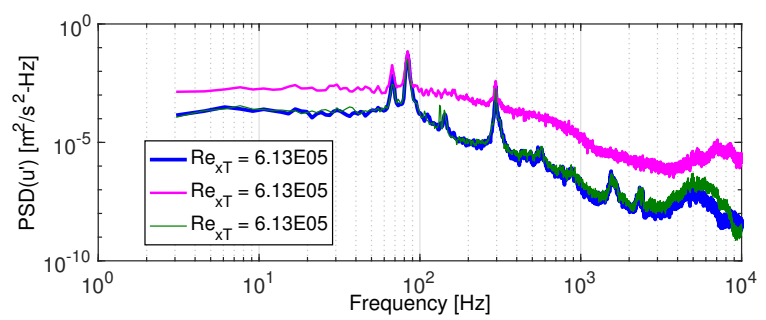

(e) case $i v\left(h / \delta_{1} \sim 0.6\right)$

Fig. 10: PSD (probed at $y=300 \mu m$ from wall) just upstream of corresponding transition location $\operatorname{Re}_{\mathrm{xT}}$ for each suction configuration for different surface defect relative height ratios. (thick blue line - no suction, medium magenta line - C1/0.400, thin green line - full suction) 
These ranges of high frequencies seem to be responsible for transition since they did not appear in any of the previous cases where transition due to TS instabilities occurred. In this case, the mechanism by which transition is triggered seems to have been modified by the presence of the surface defect. This modification can be explained by the presence of the noticeable inflection point in the mean velocity profiles immediately downstream of the wire, as seen in Figures 8(c) and 8(d). The transition mechanism seems to shift from being viscosity-driven to being the result of an inflectiontype instability [Ray80], which is generally known to be a higher frequency instability [Mac77].

The results from linear stability theory, shown for the no suction case without a surface defect and with a critical surface defect of $h / \delta_{1}$ equal to 0.43 in Figure 11, also confirm this change in transition mechanism. In both graphs, the neutral stability curve and the isocontours of the amplification $\alpha_{i}$ are plotted as a function of the nondimensional frequency $\omega$ and the displacement thickness Reynolds number, $R e_{\delta 1}$. Negative values of $\alpha_{i}$ indicate that instability waves are being amplified, since the perturbations are formulated as:

$q=\hat{q}(y) e^{-\alpha_{i} x} e^{i\left(\alpha_{r} x-\omega t\right)}$

where $q$ is any perturbation quantity. In Figure 11(d), where there is a critical surface defect and transition is due to the inflection point in the boundary layer, the range of unstable frequencies is much larger than for the no surface defect case. With the surface defect $h / \delta_{1}$ equal to 0.43 , the neutral stability curve spans over a much wider range of unstable nondimensional frequencies and these unstable frequencies are much higher than in the no surface defect case. This observation agrees with the PSD results where a range of high frequencies (above $2 \mathrm{kHz}$ ) were found to be amplified in the critical cases where transition occurred very close to the surface defect. Additionally, the absolute values of the amplification $\alpha_{i}$ are also found to be one to two orders of magnitude greater in the case of inflection-type instabilities compared to the viscosity-driven instabilities as shown in Figures 11(b) and 11(e).

Note that some PSDs in Figures 10(c) and 10(e) are shifted in amplitude with respect to the no suction case. This difference can be attributed to differences in the altitude of the hotwire during traverses. In particular, in Figure 13(e) for C1/0.400, the boundary layer thickness is significantly different from the other suction configurations, as explained above. In all these cases, the hotwire is therefore exploring slightly different relative altitudes $\mathrm{y} / \delta_{1}$ or $\mathrm{y} / \delta_{99}$ inside the boundary layer where PSD amplitude levels are different. 


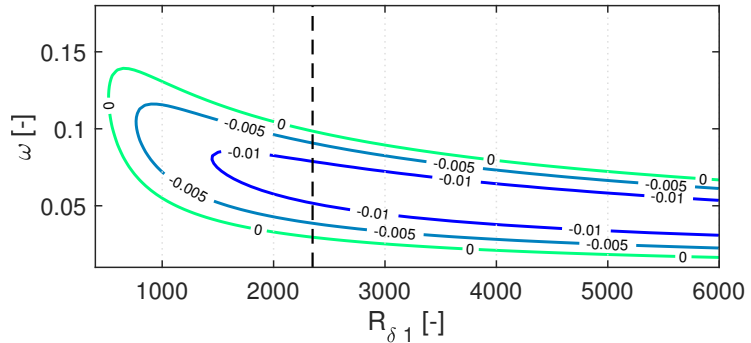

(a) no suction and no defect

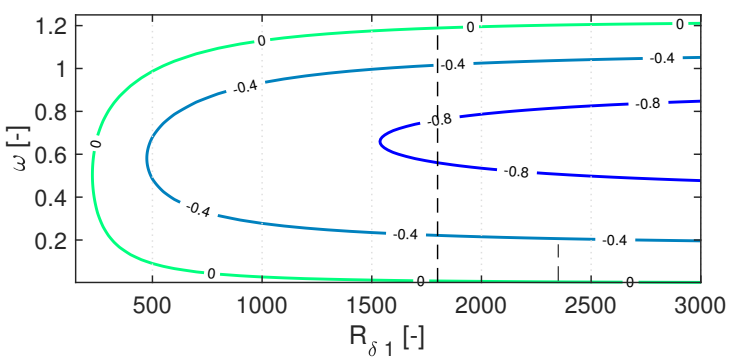

(d) no suction and critical case $i i i\left(h / \delta_{1}=0.43\right)$

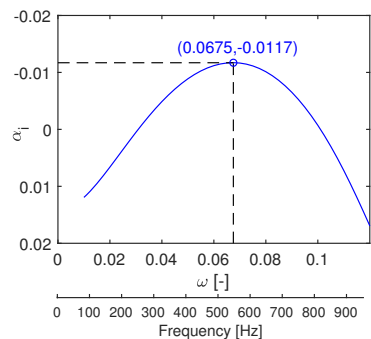

(b) $\operatorname{Re}_{\mathrm{xT}}=2200$

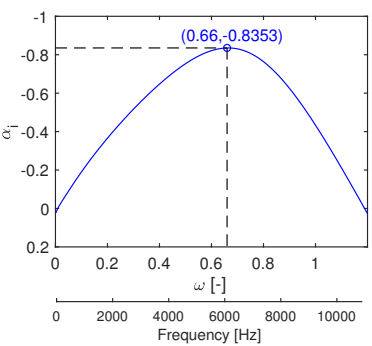

(e) $\operatorname{Re}_{\mathrm{xT}}=1800$

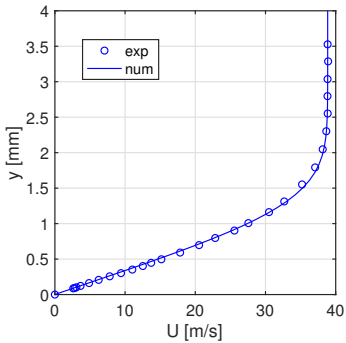

(c) Blasius profile for (a)

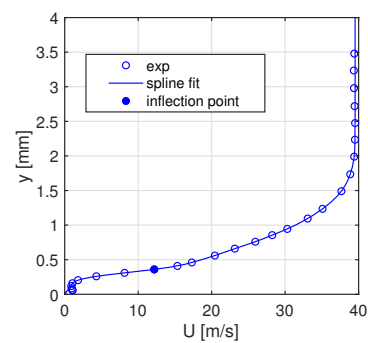

(f) Fitted profile for (c)

Fig. 11: Neutral stability curves and isocontours of the amplification $\alpha_{i}$ (the imaginary component of the wave number) from linear stability theory

\section{Conclusions}

Boundary layer suction is an effective method to delay the onset of laminar-turbulent transition. Obstacles to its more widespread use in commercial aviation are, in part, due to issues related to suction system integration and to the unreliability of current design tools. In particular, given modern manufacturing and assembly capabilities, the junction between the regions with and without suction will produce a surface discontinuity.

The flow physics of the competing effects of the stabilizing wall suction and the destabilizing surface defects on the boundary layer is complex and currently unresolved. In an effort to address these issues, the present study therefore aims at providing experimental data that characterize the effects of surface defects on the laminar-turbulent transition of a sucked boundary layer in two-dimensional incompressible flow.

Great care was taken to ensure that flow conditions in the wind tunnel were properly controlled to allow relevant investigation of the laminar-turbulent transition to be performed. Details of the experimental protocol that was developed with this intent are given in the first section. The presence of two-dimensional Blasius flow over the flat plate surface is shown so as to enable easier comparison with numerical studies.

The second part of this study involved characterizing 
the effects of boundary layer suction without any surface defects. Mass flow rate was kept constant for all suction configurations so that only suction distribution, and therefore local suction velocity, changed. First, panels with no porosity, $0.26 \%$ and $1.34 \%$ porosity were tested and found to affect transition position without suction. Although beyond the scope of this study, these preliminary results seemed to indicate that wall admittance or passive porous walls could have a destabilizing effect on laminar-turbulent transition. Next, the distribution and location of wall suction proved to have the most influence on transition position, as cases C3,5/0.200 and full suction equally moved transition furthest downstream. Spectral analysis of the flow at the point of transition for each suction configuration confirmed that transition is still a result of the amplification of TS instabilities (in this study located between $600 \mathrm{~Hz}$ and $700 \mathrm{~Hz}$ ), and that suction only delayed this moment by slowing the amplification process.

Surface defects were then introduced to the experimental set-up. For this first study, positive cylindrical roughness elements were chosen because of their single degree of freedom (diameter) and their ease of installation. Relative height with respect to the local boundary layer displacement thickness $h / \delta_{1}$ was the main parameter of interest. Results show that, for the positive surface defects studied in this paper, critical relative heights were similar between cases with and without suction. Spectral analysis also showed that, strictly below the critical relative height $h / \delta_{1}$ of 0.4 , transition was still the result of TS-waves amplification. The transition mechanism in the cases of sub-critical relative heights is therefore still related to viscosity-driven instabilities and wall suction remains effective in delaying transition. For values of $h / \delta_{1}$ greater than or equal to the critical threshold, transition occurred very close to the location of the surface defect, and seemed to occur due to the amplification of a range of high frequencies (ranging from $1.5 \mathrm{kHz}$ to $10 \mathrm{kHz}$ depending on $\left.h / \delta_{1}\right)$. Furthermore, the mean velocity boundary layer profiles immediately downstream of these surface defects showed well-defined inflection points. For these critical surface defect $h / \delta_{1}$, the mechanisms leading to transition therefore seemed to be less the result of viscosity-driven instabilities and rather the product of inflectional-type instabilities. Finally the competing effect between the reduction in boundary layer thickness $\delta_{1}$ due to wall suction and the resulting increase in $h / \delta_{1}$ in the presence of a surface defect that was highlighted in case $i v$ needs to be considered when determining critical surface defect heights. 


\section{Appendix}

The following tables provide the coordinates of the numerically optimized leading edge, shown in Figure 2(a).

\begin{tabular}{|c|c|c|c|c|c|c|}
\hline$x[\mathrm{~mm}]$ & 0 & 0.02 & 0.074 & 0.167 & 0.3 & 0.7 \\
\hline $\boldsymbol{y}[\mathbf{m m}]$ & 0 & -0.33 & -0.67 & -0.98 & -1.31 & -1.96 \\
\hline $\boldsymbol{x}[\mathbf{m m}]$ & 1.18 & 1.85 & 2.66 & 3.12 & 4.15 & 4.7 \\
\hline $\boldsymbol{y}[\mathbf{m m}]$ & -2.62 & -3.27 & -3.89 & -4.24 & -4.88 & -5.2 \\
\hline $\boldsymbol{x}[\mathbf{m m}]$ & 5.33 & 6.65 & 7.36 & 8.9 & 10.6 & 13.34 \\
\hline $\boldsymbol{y}[\mathbf{m m}]$ & -5.52 & -6.15 & -6.47 & -7.09 & -7.71 & -8.63 \\
\hline $\boldsymbol{x}[\mathbf{m m}]$ & 15.36 & 17.52 & 21 & 23.49 & 28.84 & 34.7 \\
\hline $\boldsymbol{y}[\mathbf{m m}]$ & -9.23 & -9.83 & -10.71 & -11.28 & -12.4 & -13.48 \\
\hline $\boldsymbol{x}[\mathbf{m m}]$ & 39.4 & 46.1 & 55.04 & 62.67 & 72.75 & 83.38 \\
\hline $\boldsymbol{y}[\mathbf{m m}]$ & -14.25 & -15.25 & -16.43 & -17.31 & -18.33 & -19.25 \\
\hline $\boldsymbol{x}[\mathbf{m m}]$ & 99.07 & 118 & 140.2 & 165.7 & 168.2 & 178.5 \\
\hline $\boldsymbol{y}[\mathbf{m m}]$ & -20.37 & -21.4 & -22.25 & -22.69 & -22.73 & -22.75 \\
\hline
\end{tabular}

Table 6: Leading edge coordinates on the lower side

\begin{tabular}{|c|c|c|c|c|c|c|}
\hline$x[\mathrm{~mm}]$ & 0 & 0.09 & 0.24 & 0.48 & 0.83 & 1.5 \\
\hline $\boldsymbol{y}[\mathbf{m m}]$ & 0 & 0.88 & 1.33 & 1.78 & 2.24 & 2.85 \\
\hline $\boldsymbol{x}[\mathbf{m m}]$ & 2.2 & 3.05 & 4.1 & 4.94 & 5.9 & 6.9 \\
\hline $\boldsymbol{y}[\mathbf{m m}]$ & 3.31 & 3.77 & 4.23 & 4.54 & 4.84 & 5.15 \\
\hline $\boldsymbol{x}[\mathbf{m m}]$ & 8.05 & 9.32 & 10.71 & 12.24 & 14.78 & 17.65 \\
\hline $\boldsymbol{y}[\mathbf{m m}]$ & 5.45 & 5.75 & 6.04 & 6.34 & 6.77 & 7.19 \\
\hline $\boldsymbol{x}[\mathbf{m m}]$ & 20.87 & 23.22 & 25.73 & 28.42 & 31.29 & 35.95 \\
\hline $\boldsymbol{y}[\mathbf{m m}]$ & 7.61 & 7.88 & 8.15 & 8.41 & 8.67 & 9.04 \\
\hline $\boldsymbol{x}[\mathbf{m m}]$ & 39.29 & 42.84 & 48.55 & 52.62 & 56.91 & 61.43 \\
\hline $\boldsymbol{y}[\mathbf{m m}]$ & 9.28 & 9.51 & 9.85 & 10.06 & 10.27 & 10.47 \\
\hline $\boldsymbol{x}[\mathbf{m m}]$ & 66.18 & 68.64 & 71.17 & 73.75 & 76.4 & 84.72 \\
\hline $\boldsymbol{y}[\mathbf{m m}]$ & 10.66 & 10.75 & 10.84 & 10.92 & 11 & 11.25 \\
\hline $\boldsymbol{x}[\mathbf{m m}]$ & 99.9 & 109.8 & 116.75 & 147.5 & 178.5 & \\
\hline $\boldsymbol{y}[\mathbf{m m}]$ & 11.59 & 11.77 & 11.87 & 12.17 & 12.25 & \\
\hline
\end{tabular}

Table 7: Leading edge coordinates on the upper side
The following tables provide the additional transition location data $R e_{x T}$ for the different surface defects tested on suction panels without porosity and with $1.34 \%$ porosity.

Table 8: $R e_{x T}$ for suction panel $p=1.34 \%$

\begin{tabular}{|c|c|c|c|}
\hline config & $\mathbf{0}$ (ref.) & $\sim 0.2$ & $\sim 0.4$ \\
\hline no suction & $\mathbf{1 . 3 3 \cdot \mathbf { 1 0 } ^ { 6 }}$ & $1.20 \cdot 10^{6}$ & $1.09 \cdot 10^{6}$ \\
\hline $\mathrm{C} 1 / 0.400$ & $\mathbf{1 . 5 6 \cdot 1 0 ^ { 6 }}$ & $1.48 \cdot 10^{6}$ & $1.35 \cdot 10^{6}$ \\
\hline $\mathrm{C} 3,5 / 0.200$ & $\mathbf{1 . 6 6} \cdot \mathbf{1 0}^{\mathbf{6}}$ & $1.59 \cdot 10^{6}$ & $1.43 \cdot 10^{6}$ \\
\hline full suction & $\mathbf{1 . 5 9 \cdot \mathbf { 1 0 } ^ { 6 }}$ & $1.51 \cdot 10^{6}$ & $1.33 \cdot 10^{6}$ \\
\hline
\end{tabular}

Table 9: $R e_{x T}$ for suction panel $p=0 \%$

\begin{tabular}{|c|c|c|c|}
\hline$h / \delta_{1}$ & 0 (ref.) & $\sim 0.2$ & $\sim 0.4$ \\
\hline no suction & $1.92 \cdot 10^{6}$ & $1.92 \cdot 10^{6}$ & $1.77 \cdot 10^{6}$ \\
\hline
\end{tabular}

\section{References}

[BA92] C. Bulgubure and D. Arnal. Dassault Falcon 50 laminar flow flight demonstrator. In DGLR/AAAF/RAeS 1st European Forum on Laminar Flow, 1992.

[BPFB16] S. Beguet, J. Perraud, M. Forte, and J.-Ph. Brazier. Modeling of transverse gaps effects on boundary-layer transition. Journal of Aircraft, 54(2):794-801, 2016.

[Bra99] A.L. Braslow. A history of suction-type laminar flow control with emphasis on flight research. Monographs in Aerospace History, (13), 1999. 
[Cho94] M. Choudhari. Effect of nonzero surface admittance on receptivity and stability of compressible boundary layer. 1994 .

[CP01] P.W. Carpenter and L.J. Porter. Effects of passive porous walls on boundary-layer instability. AIAA Journal, 39(4):597-604, 2001.

[CRK15] Marco Costantini, Steffen Risius, and Christian Klein. Experimental investigation of the effect of forward-facing steps on boundary layer transition. Procedia IUTAM, 14:152-162, 2015.

[DKM94] A.V. Dovgal, V.V. Kozlov, and A. Michalke. Laminar boundary layer separation: instability and associated phenomena. Progress in Aerospace Sciences, 30(1):61-94, 1994.

[Fei56] E.G. Feindt. Investigation on the dependence of laminar-turbulent transition on surface roughness and pressure gradient. Schiffbautechnischen Geselschaft Jahrbach, 50, 1956.

[Gre62] N. Gregory. On critical suction conditions for laminar boundary-layer control by suction in perforation. Technical report, Aeronautical Research Council Report No. 24, 1962.

[HCK88] R. Heinrich, M. Choudhari, and E. Kerschen. A comparison of boundary layer receptivity mechanisms. In 1st National Fluid Dynamics Conference, page $3758,1988$.

$\left[\mathrm{HDK}^{+} 10\right]$ L. Hunt, R. Downs, M. Kuester, E.B. White, and W.S. Saric. Flow quality measurements in the Klebanoff-Saric wind tunnel. In 27th AIAA Aerodynamic Measurement Technology and Ground Testing Conference, AIAA2010-4538, 2010.

[Hea55] M.R. Head. The boundary layer with distributed suction. British A.R.C. Reports \& Memoranda, (2783), 1955.
[JCA95] J.C. Juillen, G. Casalis, and D. Arnal. Aspiration discontinue : résultats expérimentaux et comparaisons aux résultats de calculs de stabilité. Technical report, CERT DERAT 107/5018.93., 1995.

[Jos98] R.D. Joslin. Overview of laminar flow control. Technical report, NASA/TP-1998-208705, 1998.

[KT72] P.S. Klebanoff and K.D. Tidstrom. Mechanism by which a two-dimensional roughness element induces boundary-layer transition. The Physics of Fluids, 15(7):1173-1188, 1972.

[Mac77] L.M. Mack. Transition and laminar instability. JPL Publication 77-15, 1977.

[Mad91] D.V. Maddalon. Hybrid Laminar Flow Control flight research. Research and Technology, NASA, TM, 4331:47, 1991.

[Mar01] J.-P. Marec. Drag reduction: a major task for research. In Aerodynamic Drag Reduction Technologies, pages 17-27. Springer, 2001.

[ME96] D.G. MacManus and J.A. Eaton. Predictions and observations of the flow field induced by laminar flow control microperforations. Experimental thermal and fluid Science, 13(4):395-407, 1996.

[MRH94] M.V. Morkovin, E. Reshotko, and T. Herbert. Transition in open flow systems-a reassessment. Bull. Am. Phys. Soc., 39:1882, 1994.

[MVFC14] J. Methel, O. Vermeersch, M. Forte, and G. Casalis. Experimental characterization of the laminar-turbulent transition of a sucked boundary layer due to surface defects in a two-dimensional incompressible flow. 2018 Flow Control Conference, AIAA AVIATION Forum, AIAA2018-3214.

[NG66] J.P. Nenni and G.L. Gluyas. Aerodynamic design and analysis of an LFC surface. Astronautics \& Aeronautics, 4(7):52, 1966. 
$\left[\mathrm{PSR}^{+} 05\right]$ J. Perraud, A. Séraudie, J. Reneaux, D. Arnal, and D. Tran. Effect of $2 \mathrm{~d}$ and $3 \mathrm{~d}$ imperfections on laminar-turbulent transition. In CEAS Katnet Conference on Key Aerodynamic Technologies, 2005.

[Ray80] J.W.S. Rayleigh. On the stability, or instability, of certain fluid motions. Proc. London Math. Soc., $9: 57-70,1880$

[RB92] J. Reneaux and A. Blanchard. The design and testing of an airfoil with hybrid laminar flow control. In $D G L R / A A A F / R A e S 1$ st European Forum on Laminar Flow, 1992.

[RSA96] H.L. Reed, W.S. Saric, and D. Arnal. Linear stability theory applied to boundary layers. Annual Review of Fluid Mechanics, 28(1):389-428, 1996.

[RV14] D.P. Rizzetta and M.R. Visbal. Numerical simulation of excrescence generated transition. $A I A A$ Journal, 52(2):385-397, 2014.

[Sar08] W.S. Saric. Experiments in 2-D boundary layers: stability and receptivity. Advances in LaminarTurbulent Transition Modelling, NATO Educational Notes, pages 8-1, 2008.

[Tan61] I. Tani. Effect of two-dimensional and isolated roughness on laminar flow. In Boundary layer and flow control, pages 637-656. Elsevier, 1961.

[TC15] N. Tilton and L. Cortelezzi. Stability of boundary layers over porous walls with suction. $A I A A$ Journal, 53(10):2856-2868, 2015.

[WG05] Y.X. Wang and M. Gaster. Effect of surface steps on boundary layer transition. Experiments in Flu$i d s, 39(4): 679-686,2005$.

[WK91] T. Watanabe and R. Kobayashi. Effect of a single roughness element on boundary layer transition over a wedge. Experimental Thermal and Fluid Science, 4(5):558-566, 1991.

[WRW03] A. Wörner, U. Rist, and S. Wagner. Humps/steps influence on stability characteristics of twodimensional laminar boundary layer. AIAA Journal, 41:192-197, 2003. 